\title{
Strength and Ductility of Stiffened Steel Box Columns of Various Cross-Sectional Configurations under Lateral Cyclic Loadings
}

\author{
T. Thevega, K. Rajavijayan, J.A.S.C. Jayasinghe and K.A.S. Susantha
}

\begin{abstract}
Stiffened steel columns are widely used in bridge piers due to their structural and constructional efficiency. The bridge pier is one of the main structural components in elevated highway transportation. The ability of structures to survive severe earthquakes depends on both strength and ductility. In this study, the stiffeners with different cross-sectional configurations are introduced to improve the strength, ductility and energy absorption capacity of thin-walled steel box columns. All cross-sections are designed with the same cross-sectional area and height for different stiffener arrangements. The columns are analysed by finite element method, incorporating both material and geometric nonlinearities under constant axial load and lateral cyclic loading. Using the lateral loadlateral displacement behaviour, the cross-section with two middle stiffeners shows high strength and ductility capacity. But examining energy absorption behaviour, the cross-section with corner stiffener shows high capacity among analysed columns. Therefore, by considering strength, ductility and energy absorption capacity, the best cross-section is identified as the cross-section with two middle stiffener arrangement with a particular cross-sectional area compared with other cross-sections. In addition to that, local buckling patterns of the columns are examined at different displacement levels to understand the failure modes.
\end{abstract}

Keywords: Bridge pier, Cyclic loading, Strength, Ductility, Nonlinear finite element analysis, Stiffened steel column, Steel material model

\section{Introduction}

Steel bridge piers, with either circular, square or rectangular cross-sections, are widely used as part of the lateral and vertical force-resisting systems in buildings, offshore platforms, elevated storage tanks and transmission towers, or as cantilever piers in bridges and wind turbines [1]. Steel columns may be superior to the counterparts of reinforced concrete due to the stiffness, lightweight and ductility, especially when limited construction space is preferable [2].

The most common failure mode of steel columns of highway bridge piers is lateral deformation due to local buckling of steel plates when subjected to lateral cyclic loading. Local buckling and global buckling are the main reasons for the reduction in strength and ductility in columns, which causes failure under lateral cyclic loadings.

There are several methods to delay the buckling of steel plates [3]. Commonly used methods are concrete infilling or introducing stiffeners [4], [5], [6], [7]. In the past, many studies have shown that the performance of concrete-filled hollow box sections are not good because local buckling is most likely to occur in box tubes [8]. Although concrete infilling delays local buckling of steel plates, to make it more effective, longitudinal stiffeners can be welded inside or outside the steel plate [9]. Introducing only the stiffeners could also be used to delay the local buckling of steel bridge piers. Diaphragms can also be placed horizontally along the column to delay local buckling.

Eng. (Miss.) T. Thevega, B.Sc. Eng. (Hons) (Peradeniya), Temporary Instructor in Department of Civil Engineering, University of Peradeniya, Sri Lanka.

Email: thevegat@eng.pdn.ac.lk

ORCID ID: https://orcid.org/0000-0001-7939-2876

Eng. (Miss.) K. Rajavijayan,B.Sc. Eng. (Hons) (Peradeniya), Civil Engineer in State Development and Construction Corporation, Ratmalana, Sri Lanka.

Email:keshangir@eng.pdn.ac.lk

ORCID ID:http://orcid.org/0000 00023129 510X

Eng. (Dr.) J.A.S.C. Jayasinghe, B.Sc. Eng. (Hons) (Peradeniya), M.Eng. (AIT), PhD. (Tokyo), Senior Lecturer in Department of Civil Engineering, University of Peradeniya, Sri Lanka.

Email:supunj@pdn.ac.lk

ORCID ID: http://orcid.org/0000_0003_1054_9358

Prof. K.A.S. Susantha, B.Sc. Eng. (Hons) (Peradeniya), M.Eng. (AIT), D. Eng. (Nagoya), Professor in Department of Engineering Mathematics, University of Peradeniya, Sri Lanka.

Email:samans@pdn.ac.lk

ORCID ID: http://orcid.org/0000-0002-1699-9264 
Several experimental studies have been carried out to analyse the behaviour of the column on seismic performance [10], [11]. Those tests were found to be very costly and results were not adequate to make a firm conclusion. Therefore, the analytical procedure is important in this type of investigation.

The aim of this study is to propose an optimum cross-sectional configuration that gives high strength, ductility and energy dissipation capacity of steel bridge piers. For this purpose, stiffened steel columns having different crosssectional configurations are analysed. The analyses are carried out using a finite element model which considers the effects of both material and geometric nonlinearities. The reliability of prediction of this type of investigation highly depends on the details of the finite element model such as material models, element types and mesh, boundary conditions, solution technique, etc.

When steel material models are considered, yielding criteria and hardening models play a great role. In this study, commonly used three models, namely isotropic, kinematic and combined hardening, are used in the analyses. Analyses are carried out using afinite element program called ABAQUS.

\section{Finite Element Analysis of Steel Column}

There are several analytical methods that have been developed to employ nonlinear simulation. The empirical model, plastic hinge model and elasto-plastic finite element model are some of the recognized methods [12]. The finite element methods which account for both geometric and material nonlinearities are comparatively more accurate and the accuracy greatly depends on the ability of the material model to simulate real material behaviour.

In this study, afinite element model is developed in ABAQUS for a previously tested stiffened steel box column [13]. The analysis is carried out simulating the same loading pattern of the test with three different material models. The comparisons are made between the test and the predicted results. The material model that gives the best prediction is selected for the subsequent analyses of the different cross-sectional configurations.

\subsection{Details of the Steel Column}

Different cross-sectional configurations are proposed by changing the stiffener arrangement inside the column, as shown in Figure 1. The selected test specimen has eight stiffeners similar to the cross-section type 4 . Crosssectional details of the specimens are shown in Table 1.

The cross-sectional area is kept constant $\left(A_{S}=12800 \mathrm{~mm}^{2}\right)$ and the height of the columns is $2420 \mathrm{~mm}$. The main plates, stiffeners and diaphragms are of SM490 steel type (Japanese Industrial Standard). Three horizontal diaphragms are provided in an interval of $450 \mathrm{~mm}$ from the base of the column. All the component plates (i.e., main plates, longitudinal stiffeners and diaphragms) have welded connections.

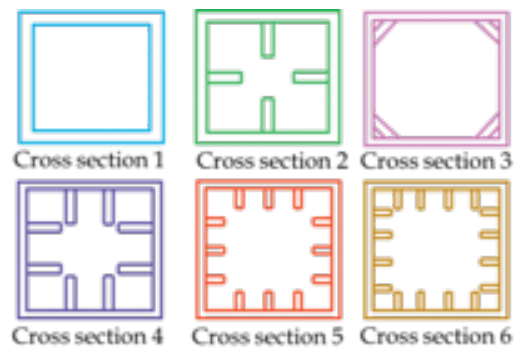

Figure 1 - Different Types of Cross-Section

Table 1 - Cross-Sectional Details of Columns

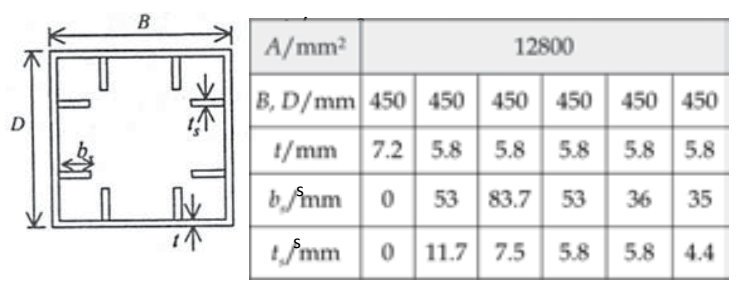

\subsection{Finite Element Model}

The steel columns are modeled using a 4-node shell element (S4R) available in ABAQUS program. One of the most important aspects that affects accuracy in numerical methods is mesh sensitivity. Usually, when mesh density increases, the quantity of interest starts to converge to a particular value. However, there is a point where a further increase of the number of elements would not yield any benefit in terms of accuracy.

The optimum element mesh is identified after carrying out a series of analyses. Accordingly, very finer mesh is employed near the base where high stresses and local buckling are expected to occur while the upper part is modelled with a coarser mesh to increase the computational efficiency, as shown in Figure 2. The transition from finer to coarser mesh is carried out using the same type of shell element while ensuring the nodal and edge compatibilities. 


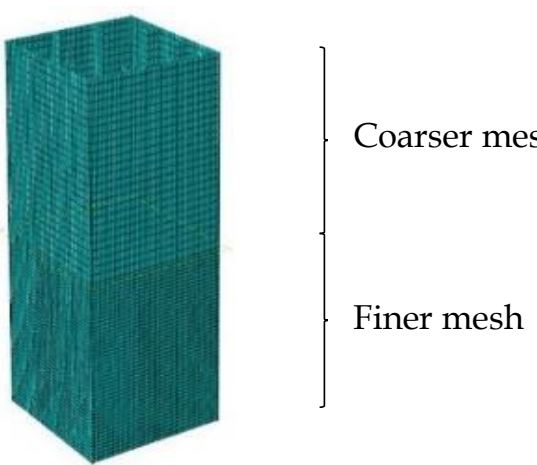

Figure 2 - Finite Element Mesh

\subsection{Material Model}

Modern design specification allows steel structures to deform up to a certain displacement level in the inelastic range, which involves both material and geometrical nonlinearity. In a non-linear analysis, the accuracy of the model has a large effect on the reliability of predictions. Yield function, flow rule and hardening are important factors in material nonlinearity. There are some yield criterions to define yield surface where material undergoes yielding such as Von Mises, Tresca, MohrCoulomb etc. Von Mises yield criterion, which is commonly used in steel material modelling, is used in this study.

The flow rule defines the plastic straining. After yielding, there is a permanent deformation in the material that is plastic deformation. Hardening is defined as the change of yield surface as material yields. There are three different hardening rules that are commonly used [14], namely Isotropic Hardening (IH), Kinematic Hardening $(\mathrm{KH})$ and Combined Hardening $(\mathrm{CH})$.

Bauschinger effect is neglected in the IH model and in the $\mathrm{KH}$ model, constant. The isotropic hardening rule states that the yield surface expands proportionally in all directions when yield stress is exceeded. Stress induces an anisotropic effect. That is known as the Bauschinger effect. Kinematic hardening involves a translation of the yield surface. The combined hardening rule states that the yield surface expands and translates in the direction of the stress rising.

In this study, all three types of hardening rules are incorporated together with the elasto-plastic bilinear stress-strain model shown in Figure 3 [15]. Bilinear idealization is made from the trilinear model by connecting the yield point with the point at $5 \%$ strain. The material parameters corresponding to the tri-linear idealization of SM490 steel is given in Table 2.

Table 2 - Material Properties

\begin{tabular}{|l|l|}
\hline \multicolumn{2}{|c}{ Steel type SM490 } \\
\hline \multicolumn{1}{|c|}{ Parameter } & \multicolumn{1}{c}{ Value } \\
\hline Yield stress $\left(\sigma_{y}\right)$ & $412 \mathrm{MPa}$ \\
\hline Young modulus $\left(E_{s}\right)$ & $206000 \mathrm{MPa}$ \\
\hline Poission ratio $(v)$ & 0.276 \\
\hline$\varepsilon_{s t} / \varepsilon_{y}$ & 7 \\
\hline$E_{s t} / E_{s}$ & $1 / 30$ \\
\hline
\end{tabular}

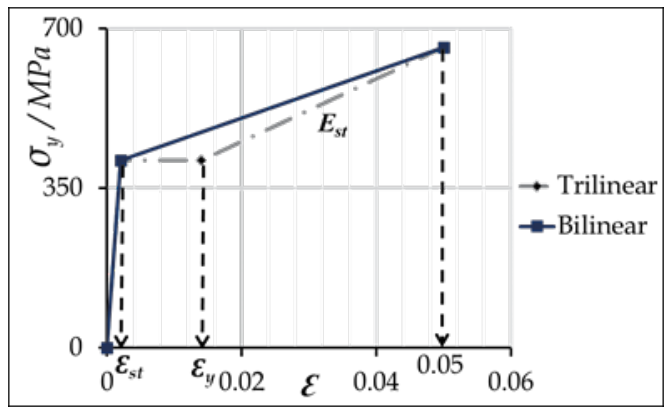

Figure 3 - Steel Material Model (Susantha et al., 2001)

\section{$2.4 \quad$ Loading}

The loading pattern as adopted in the test arrangement is used in all the analyses [13]. First, the axial load $P$ is applied as $0.2 P_{y}\left(P_{y}=A_{s} \sigma_{y}\right.$, where $A_{s}$ is the cross-sectional area) at the column top. Then the lateral cyclic displacement is incrementally applied at the column top for all the columns with different cross-sectional configurations, as illustrated in Figure 4.

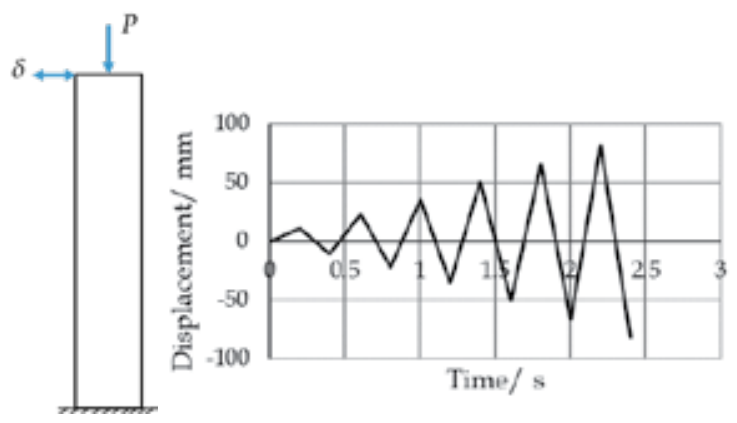

Figure 4 - Loading Arrangement

\section{Results}

\subsection{Validation of the Model}

The lateral load-lateral displacement hysteretic curves (normalized by $H_{y}$ and $\delta_{y}$ ) for all the models are obtained from the analyses. Comparisons (hysteretic curves and envelope curves) of the experimental and predicted relations using $\mathrm{IH}, \mathrm{KH}$, and $\mathrm{CH}$ material models are shown in Figure 5. 
It is visible that the $\mathrm{CH}$ model gives comparatively better comparison with experimental results. The high discrepancy of maximum load observed with the IH model is attributed to the isotropic expansion of the yield surface. In the case of comparisons with $\mathrm{KH}$ and $\mathrm{CH}$ models, the initial stiffness and loading/unloading stiffness are found to be reasonably acceptable. The difference between experimental and analysis for the $\mathrm{CH}$ model is smaller than the $\mathrm{KH}$ model. In this study, the $\mathrm{CH}$ model is identified as the most suitable material model to be used in the rest of the finite element analyses.

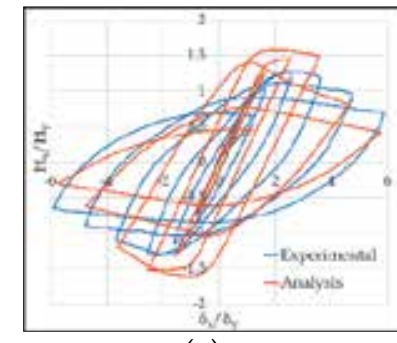

(a)

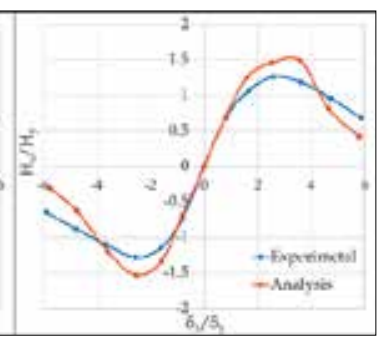

(d)
Isotropic Hardening Model

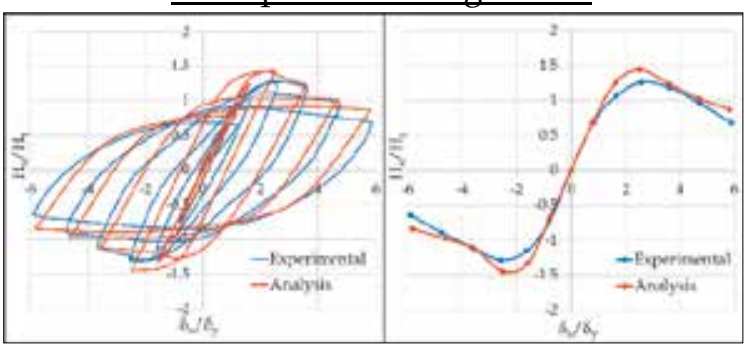

(b)

(e)

Kinematic Hardening Model

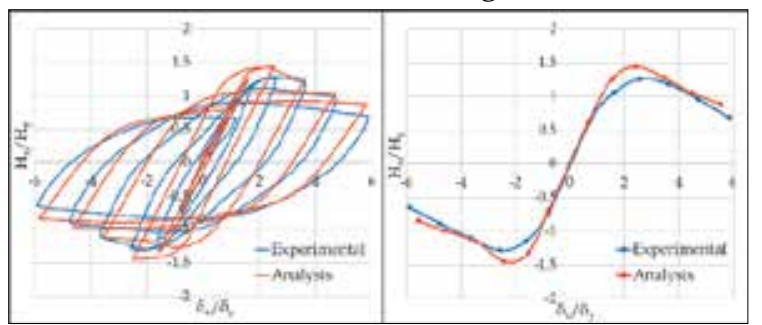

(c)

Combined Hardening Model

Figure 5 - Lateral Load-Lateral Displacement Relations: Experimental vs Prediction using: (a), (b) and (c) Hysteresis Curves (d), (e) and (f) Envelope Curves

The deformed shapes obtained at lateral displacement level of $65.6 \mathrm{~mm}$ using three material models are shown in Figure 6. It is observed that the magnitude and shape of buckling are different for different material models. Generally, buckling occurs near the base of the column. However, for the IH model, when the lateral displacement is increased it moves up

from the base, possibly due to strain hardening around the base [16].
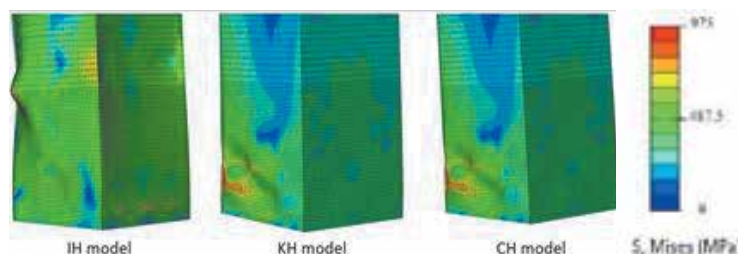

Figure 6 - Deformed Shapes of the Column

\subsection{Strength and Ductility Evaluation of Different Cross-Sectional Configurations}

Lateral load-lateral displacement hysteresis curves and envelope curves for different crosssectional configurations using Combined Hardening $(\mathrm{CH})$ model are shown in Figures 7 and 8 , respectively. As seen in these figures, the initial stiffness (load-displacement behaviour) is similar for all the cross-sectional configurations.

The cross-section 1 experiences faster strength degradation after initiation of local buckling because there are no stiffeners to prevent the buckling. It is clearly observed from the comparison of envelope curves that the stiffness and strength can be improved and the occurrence of local buckling could be delayed by changing the stiffener arrangement, as shown in Figure 8 .

The load-carrying capacity of the cross-section 3 decreases smoothly after buckling due to corner strengthening plates even though it could not bear a large lateral load than cross-sections 4, 5 and 6 . However, after undergoing a large lateral displacement of around $4.5 \delta_{y}$, it shows better performance than the cross-sections 5 and 6 . Among all different cross-sections, the crosssection 4 shows better performance under lateral cyclic loading.

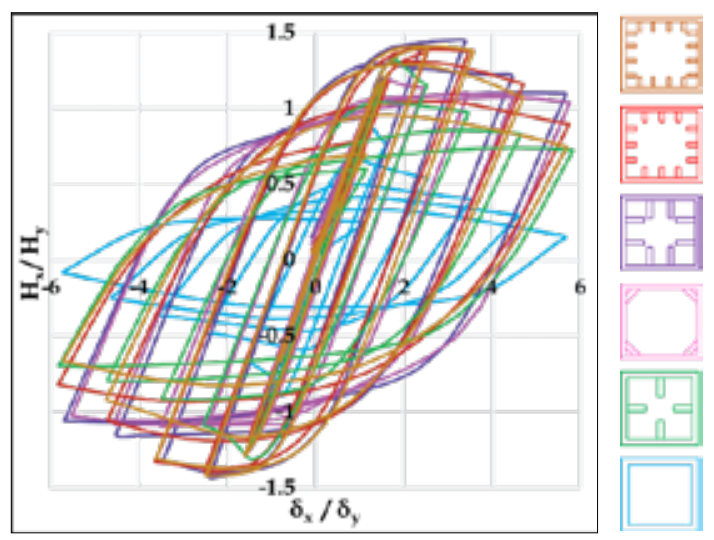

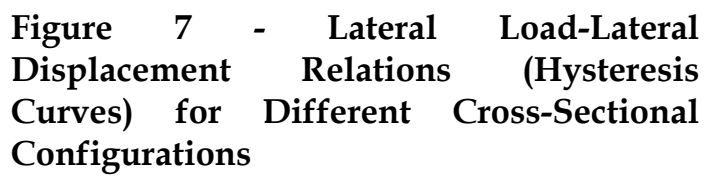




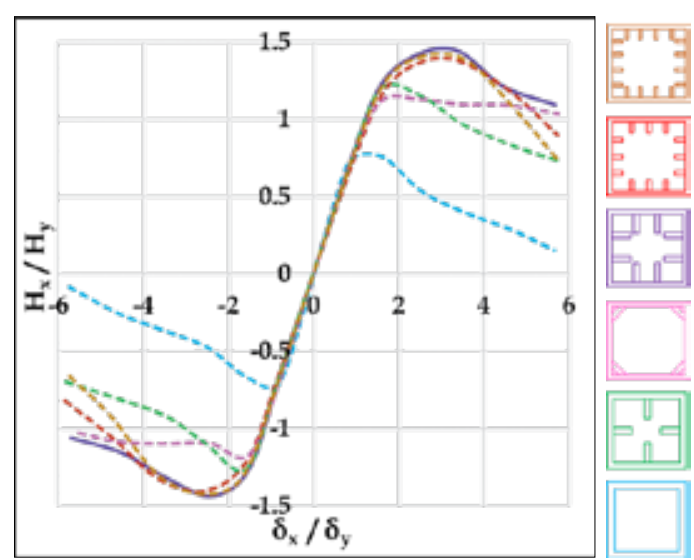

Figure 8 - Lateral Load-Lateral Displacement Relations (Envelope Curves) for Different Cross-Sectional Configurations

The deformed shapes are obtained at maximum lateral displacement level $(\delta=81.48 \mathrm{~mm})$ for different cross-sectional configurations in the $\mathrm{CH}$ model (see Figure 9). Figure 9(a) shows significant deformation near the base of the unstiffened section. Ductility is the ability of a structure to resist large deformations. The ductility of the column is improved by increasing longitudinal resistance with longitudinal stiffeners. The columns, which have stiffeners in the middle of the plates, show different local buckling patterns. There seems to be a correlation between local buckling patterns and the performance which needs to be studied in a future comprehensive study.

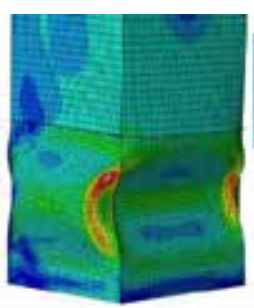

(a)

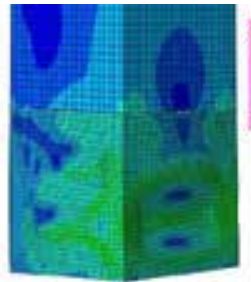

(c)

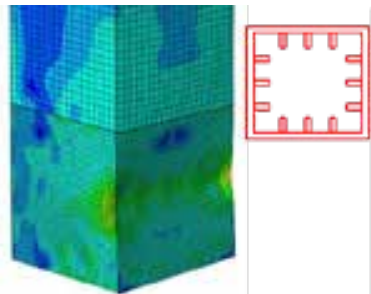

(e)
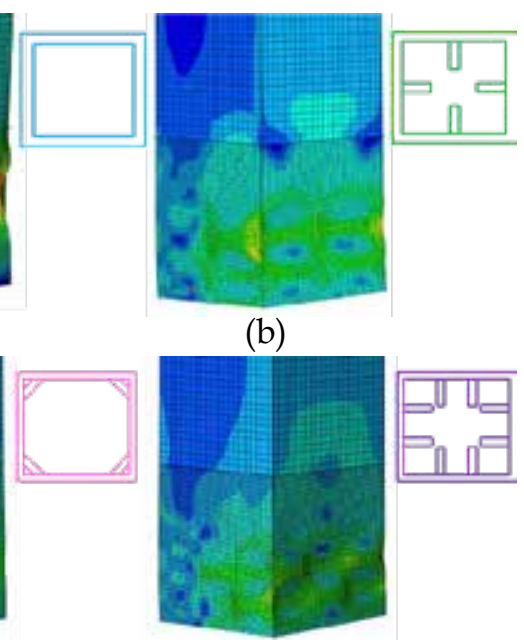

(d)

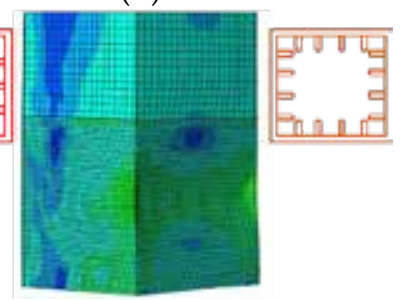

(f)
Figure 9 - Deformed Shape of Different Cross-Sectional Configurations

\subsection{Energy Absorption Capacity}

The dissipated energy is a measure of the cyclic behaviour of the structures. A normalized energy absorption $(E)$ is defined in Eq. (1) [17].

$$
E=\frac{2}{H_{y} \delta_{y}} \sum_{n=1}^{n} E_{i}
$$

In Eq. (1), $E_{i}=$ energy absorption in the $i^{\text {th }}$ halfcycle, $n=$ number of half-cycles (one-half cycle is defined from any zero-lateral load to the subsequent zero-lateral load). The dissipated energy can also be calculated by the summation of the area of full cycles under lateral load-lateral displacement curves. The strength of the column decreases at a controlled rate from cycle to cycle, which is expected to dissipate larger energy under cyclic lateral loading. If the dissipated energy is larger, itis expected to experience higher ductility [18].

Ductility is always a big concern for structures in regions of high seismicity. It seems that more attention should be directed to the problem of poor ductility of the thin-walled steel columns. The energy absorption capacity of the column for different cross-sectional configurations is evaluated under lateral cyclic loadings.

Figure 10 shows the comparison of the variation of cumulative energy absorption with the number of lateral cycles obtained. The dissipated energy is higher for cross-section 6 than cross-sections 1 and 2. However, it is lower than cross-section 3 . Further, cross-sections 4,5 and 6 dissipate nearly same amount of energy. Even though the strength of the column with cross-section 3 is lower than the cross-sections 5 and 6 (see Figure 8), ductility and energy absorption of the column with cross-section 3 is higher than those of cross-sections 5 and 6 (see Figure 10).

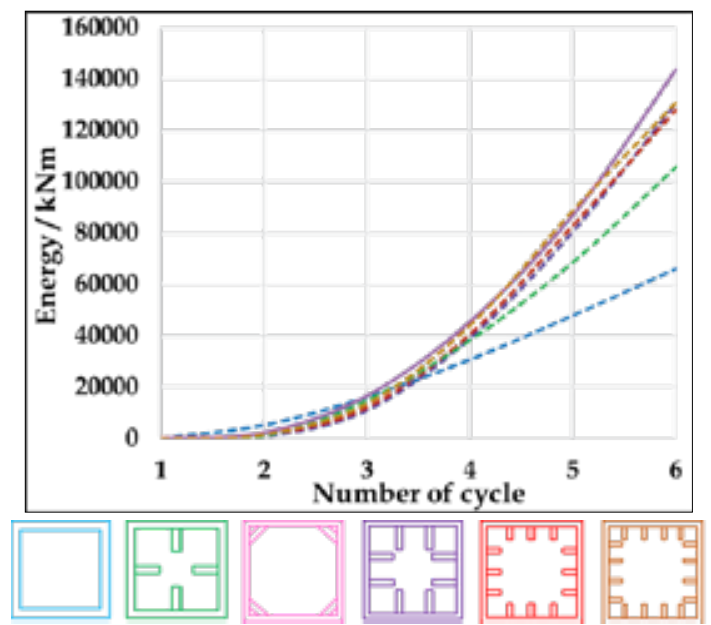

Figure 10 - Energy Absorption Capacity of different Cross-Sectional Configurations 
Effect of Different Lateral Cyclic Loadings with Different CrossSectional Configurations

The analyses are carried out for four types of lateral cyclic loading patterns from past literature [1], [2], [11] as illustrated in Figure 11, to investigate the effect of lateral loading patterns on the column behavior. However, lateral displacements are given according to the experimental displacements. Since the actual loading patterns under real earthquake loads are complex, investigation of behavior under different loading patterns is very important.

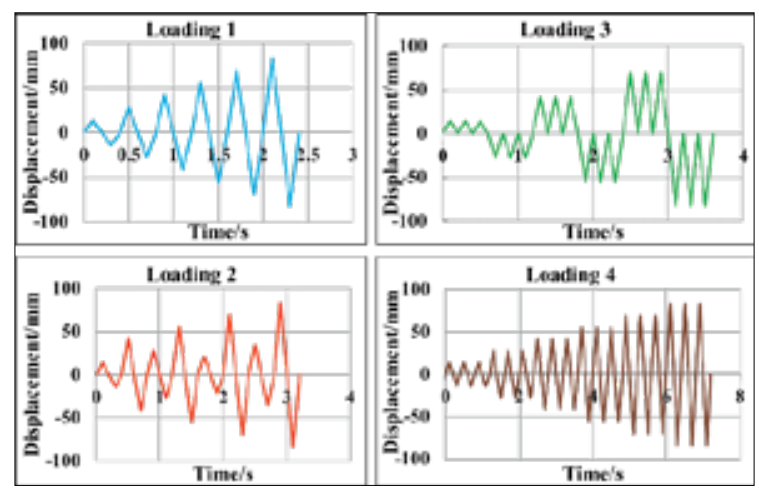

Figure 11 - Different Types of Lateral Cyclic Loadings

The effects of loading patterns under different cross-sectional configurations are studied. The envelope curves of the corresponding hysteretic curves are shown in Figure 12 for different crosssections. There is no significant effect on the maximum lateral load for a particular crosssection, but the slope of post-peak curves differs when different loading patterns are used. This is a very important observation because lateral displacements of the column should be predicted using a loading pattern that suits best the actual displacement patterns of the column subjected to a particular earthquake.

\subsection{Optimum Stiffener Arrangement}

It is clearly visible that the strength, ductility and energy absorption capacity increase with the number of stiffeners but, after a particular number, the performance gradually diminished because when the number of stiffeners increased while keeping steel cross-sectional area constant, the size of the stiffeners becomes significantly small. To check this, an additional crosssectional configuration (five stiffeners per side) is selected, as shown in Figure 13.

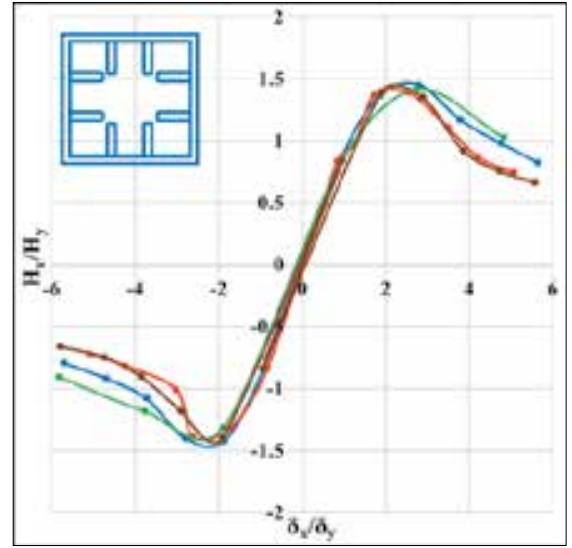

(a)

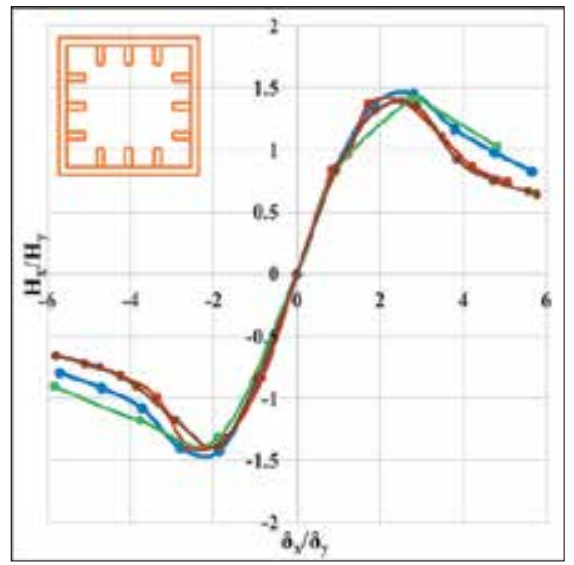

(b)

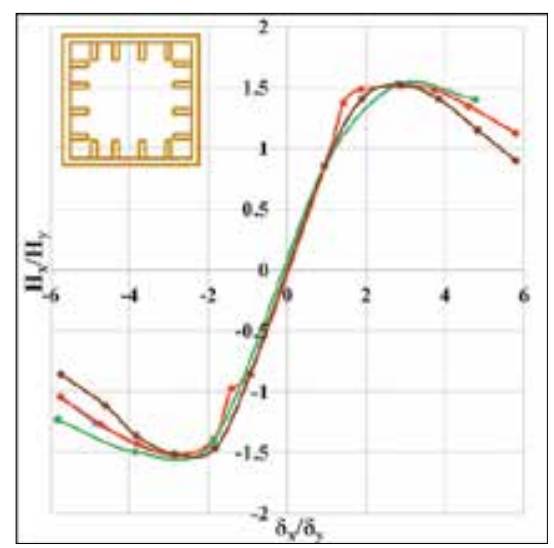

(c)

Figure 12 - Lateral Load-Lateral Displacement Relations (Envelope Curves) for different Cross-Sectional Configurations with different Lateral Cyclic Loadings

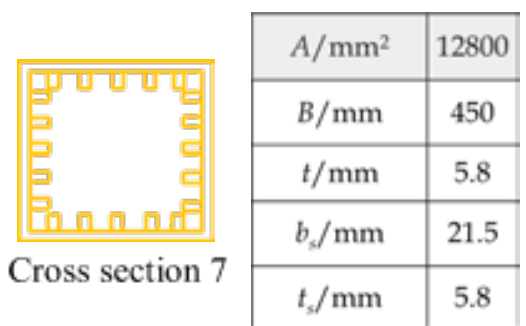

Figure 13 - The Cross-Sectional Details of the Additional Column 
When increasing the number of stiffeners from four to five, the strength decreases by $12 \%$ (see Figure 14) and energy absorption capacity reduces by $15 \%$ (see Figure 15). Up to four stiffener arrangement, buckling occurs at the later part of cycles but for five stiffener arrangement, buckling occurs at the early stage of cycles.

Even though the thickness of the outer plate and thickness of stiffeners are same for the crosssections 4 and 5 , when the length of the stiffeners are reduced by $32 \%$ (changing the number of stiffeners with the same cross-sectional area), the strength is reduced by $3 \%$ and also energy absorption capacity is reduced by $3 \%$. Based on the performance in terms of strength, ductility and energy absorption ability, the cross-section with two stiffeners per side is identified as the optimum stiffener arrangement out of all the configurations considered in this study.
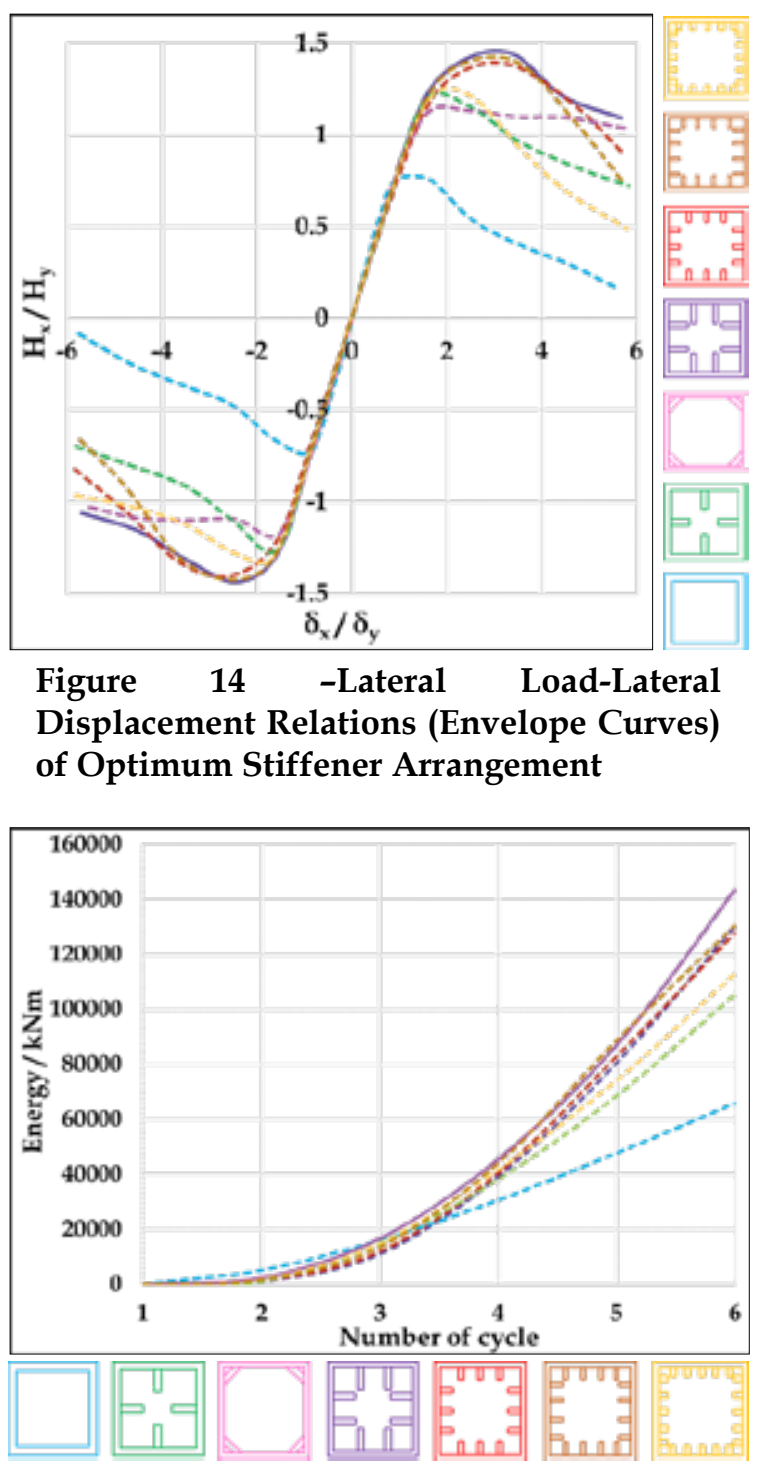

Figure 15 - Energy Absorption Capacity of Optimum Stiffener Arrangement

\section{Conclusions}

In this study, numerical analysis has been carried out to evaluate the cyclic behaviour of the steel column using finite element analysis. First, the effects of material models on hysteretic response are investigated using three material models. Then, different cross-sectional configurations are introduced with the same cross-sectional area to improve the strength, ductility and buckling behaviour of the column under constant axial and lateral cyclic loading. The followings are the main conclusions of this study;

- The proposed finite element analysis procedure can be used to determine the strength, ductility and energy absorption capacity of a steel column.

- Among the three hardening models, Combined Hardening $(\mathrm{CH})$ model gives better prediction, which is suitable for proposed finite element analyses.

- The cyclic behavior of the steel column is improved with stiffeners. The crosssection 1 does not have stiffeners on the plates to delay the local buckling and to improve the strength of the column.

- Under different lateral cyclic loadings, the performance of the column is dependent on the cross-section.

- The cross-section 3 has only corner plates that helped to increase the ductility significantly compared to other cross-sections. However, the strength increase is not significant in crosssection 3 . Therefore, an attempt should be made to check a cross-section with both corner plates and one or several stiffeners per side.

- The cross-section 4 with two middle stiffeners shows better strength and ductility performance in comparison with other cross-sections.

- It is important to have corner stiffeners in the columns to have stable post-peak load-displacement behavior as evident from the lateral load-lateral displacement curves (hysteresis curves and envelope curves) corresponding to the cross-section 3.

- It is important to have stiffeners on the middle of the plates to resist maximum lateral load, that is proved by the lateral load-lateral displacement curves (hysteresis curves and envelope curves) corresponding to cross-sections 4,5 and 6. 
- In stiffened steel columns, strength and ductility increase with the number of stiffeners. However, there is a limitation on the number of stiffeners.

- This method can be used in the bridge construction industry to find the optimum cross-section for a given crosssectional area by considering lateral performance.

\section{Acknowledgement}

The authors would like to give their acknowledgement for licensed applications of the ABAQUS package facilitated by the Finite Element Analysis and Simulation Centre, Rubber Research Institute of SriLanka, Ratmalana.

\section{References}

1. Ucak, A. and Tsopelas, P., “Load Path Effects in Circular Steel Columns under Bidirectional Lateral Cyclic Loading", Journal of Structural Engineering, 2015.

2. Al-Kaseasbeh, Q. and Mamaghani, P.H.I., "Buckling Strength and Ductility Evaluation of Thin-Walled Steel Stiffened Square Box Columns with Uniform and Graded Thickness under Cyclic Loading", Engineering Structures 186, 2019, pp. 498-507.

3. Mamaghani, P. H. I., "Seismic Design and Retrofit of Thin-Walled Steel Tubular Columns", $13^{\text {th }}$ World Conference on Earthquake Engineering, 2004.

4. Aizhu, Z., Hongping, Z., Xiaowu, Z. and Yong, L., "Experimental Study and Analysis of Inner Stiffened Cold Formed SHS Steel Stub Columns", Thin-walled structures 107, 2016.

5. Zheng, Y., Usami, T. and Ge, H., "Ductility of Thin-Walled Steel Box Stub Columns", Journal of Structural Engineering, 2000.

6. Astaneh- Asl, A. and Qian, X., “Behaviour and Seismic Design of Stiffeners for Steel Bridge Tower Legs and Piers", $16^{\text {th }}$ Conference on Civil, Structural and Environmental Engineering, ICSENM 117, 2016.

7. Nishikawa, K., Yamamoto, S., Natori, T. and Yasunami, H., "Retrofitting for Seismic Upgrading of Steel Bridge Piers", Engineering Structures, 1998.

8. Tao, Z., Han, L. H. and Wang, D. Y., "Experimental Behaviour of Stiffened
Concrete-Filled Thin-Walled Hollow Structural Steel (HSS) Stub Column", Journal of Structural Steel Research, 2015.

9. Tao, Z., Han, L. H. and Wang D. Y., "Strength and Ductility of Stiffened ThinWall Hollow Steel Structural Stub Columns Filled with Concrete", Thin-wall Structures 46(10), 2008.

10. Aoki, T. and Susantha, K. A. S., "Seismic Performance of Rectangular Shaped Steel Piers under Cyclic Loading", Journal of Structural Engineering, 2005.

11. Kumar, S. and Usami, T., "Damage Evaluation in Steel Box Columns by Cyclic Loadings", Journal of Structural Engineering, 1996.

12. Gao, S., Usami, T. and Ge, H., "Ductility Evaluation of Steel Bridge Piers with Pipe Sections", Journal of Engineering Mechanics, 1998, pp. $260-267$.

13. Susantha, K. A. S., Aoki, T. and Jayasinghe, R.T.M., "Finite Element Analysis of Steel Columns Subjected to Bi-directional Cyclic Loads", Journal of Institution of Engineers, 2007, pp. 35-41.

14. Usami, T. and Ge, B. H., "Cyclic Behavior of Thin-Walled Steel Structures- numerical analysis", Thin-walled Structures 32, 1998.

15. Susantha, K. A. S., Ge, H. and Usami, T., “A Capacity Prediction Procedure for Concrete Filled Steel columns", Journal of Earthquake Engineering, vol. 5, 2001, pp.483-520.

16. Rajavijayan, K., Thevega, T., Jayasinghe, J. A. S. C. and Susantha, K. A. S., "Performance of Steel Bridge Piers using Lateral Cyclic Load Analysis", $10^{\text {th }}$ International Conference on Structural Engineering and Construction Management, 2019.

17. Mamaghani, I., Usami, T. and Mizuno, E., "Cyclic Elastoplastic Large Displacement Behaviour of Steel Compression Members", Journal of Structural Engineering, vol. 42, 1996, pp.135-145.

18. Al-Kaseasbah, Q. and Mamaghani, P. H. I., "Design and Cyclic Elasto-plastic Analysis of Graded Thin-Walled Steel Tubular Columns with Enhanced Strength and Ductility", International Journal of Modern Engineering, vol.19, No. 3, 2018. 